\title{
Future Perspectives: Therapeutic Targeting of Notch Signalling May Become a Strategy in Patients Receiving Stem Cell Transplantation for Hematologic Malignancies
}

\author{
Elisabeth Ersvaer, ${ }^{1}$ Kimberley J. Hatfield, ${ }^{1}$ Håkon Reikvam, ${ }^{1}$ and Øystein Bruserud ${ }^{1,2}$ \\ ${ }^{1}$ Division of Hematology, Department of Medicine, Haukeland University Hospital and Institute of Medicine, \\ University of Bergen, N-5021 Bergen, Norway \\ ${ }^{2}$ Medical Department, Haukeland University Hospital, N-5021 Bergen, Norway
}

Correspondence should be addressed to Øystein Bruserud, oystein.bruserud@helse-bergen.no

Received 26 July 2010; Accepted 30 August 2010

Academic Editor: Joseph H. Antin

Copyright ( $) 2011$ Elisabeth Ersvaer et al. This is an open access article distributed under the Creative Commons Attribution License, which permits unrestricted use, distribution, and reproduction in any medium, provided the original work is properly cited.

\begin{abstract}
The human Notch system consists of 5 ligands and 4 membrane receptors with promiscuous ligand binding, and Notch-initiated signalling interacts with a wide range of other intracellular pathways. The receptor signalling seems important for regulation of normal and malignant hematopoiesis, development of the cellular immune system, and regulation of immune responses. Several Notch-targeting agents are now being developed, including natural receptor ligands, agonistic and antagonistic antibodies, and inhibitors of intracellular Notch-initiated signalling. Some of these agents are in clinical trials, and several therapeutic strategies seem possible in stem cell recipients: (i) agonists may be used for stem cell expansion and possibly to enhance posttransplant lymphoid reconstitution; (ii) receptor-specific agonists or antagonists can be used for immunomodulation; (iii) Notch targeting may have direct anticancer effects. Although the effects of therapeutic targeting are difficult to predict due to promiscuous ligand binding, targeting of this system may represent an opportunity to achieve combined effects with earlier posttransplant reconstitution, immunomodulation, or direct anticancer effects.
\end{abstract}

\section{Introduction}

The most important members of the human Notch system are the four Notch receptors and their five ligands. Notch-mediated signalling is important in embryonic hematopoiesis and development of the immune system, regulation of the peripheral immune system, and development of hematological malignancies, especially $\mathrm{T}$ cell acute lymphoblastic leukemia (T-ALL) [1-3]. Thus, for patients treated with allogeneic stem cell transplantation for hematological malignancies, agonistic or antagonistic targeting of Notch signalling may become useful to (i) achieve more effective and safe antileukemic treatment and thereby reduce the risk of posttransplant relapse through direct targeting of the malignant cells, (ii) enhance $\mathrm{T}$ cell reconstitution and thereby reduce posttransplant immune defects, and (iii) develop new immunomodulatory strategies that can reduce the risk of severe infections and severe graft versus host disease (GVHD) without inhibition of graft versus leukemia (GVL) effects. Even a combination of these effects may become a possible treatment by careful selection of molecular targets.

\section{Notch Molecules, Notch Ligands, and Downstream Signalling}

2.1. Notch and Notch Ligands. Humans possess the four heterodimeric transmembrane Notch receptors Notch1-4 that can bind the five transmembrane ligands Delta-like 1, 3 , and 4 (DLL1/3/4) and Jagged 1 and 2 (JAG1/2) (Figure 1). The receptor chains are cleaved by a furin-like protease in the Golgi apparatus during their way to the cell surface where they form heterodimeric receptors. These receptors consist of an extracellular subunit (NEC) with a distant part with a variable number of glycosylated Epithelial growth 


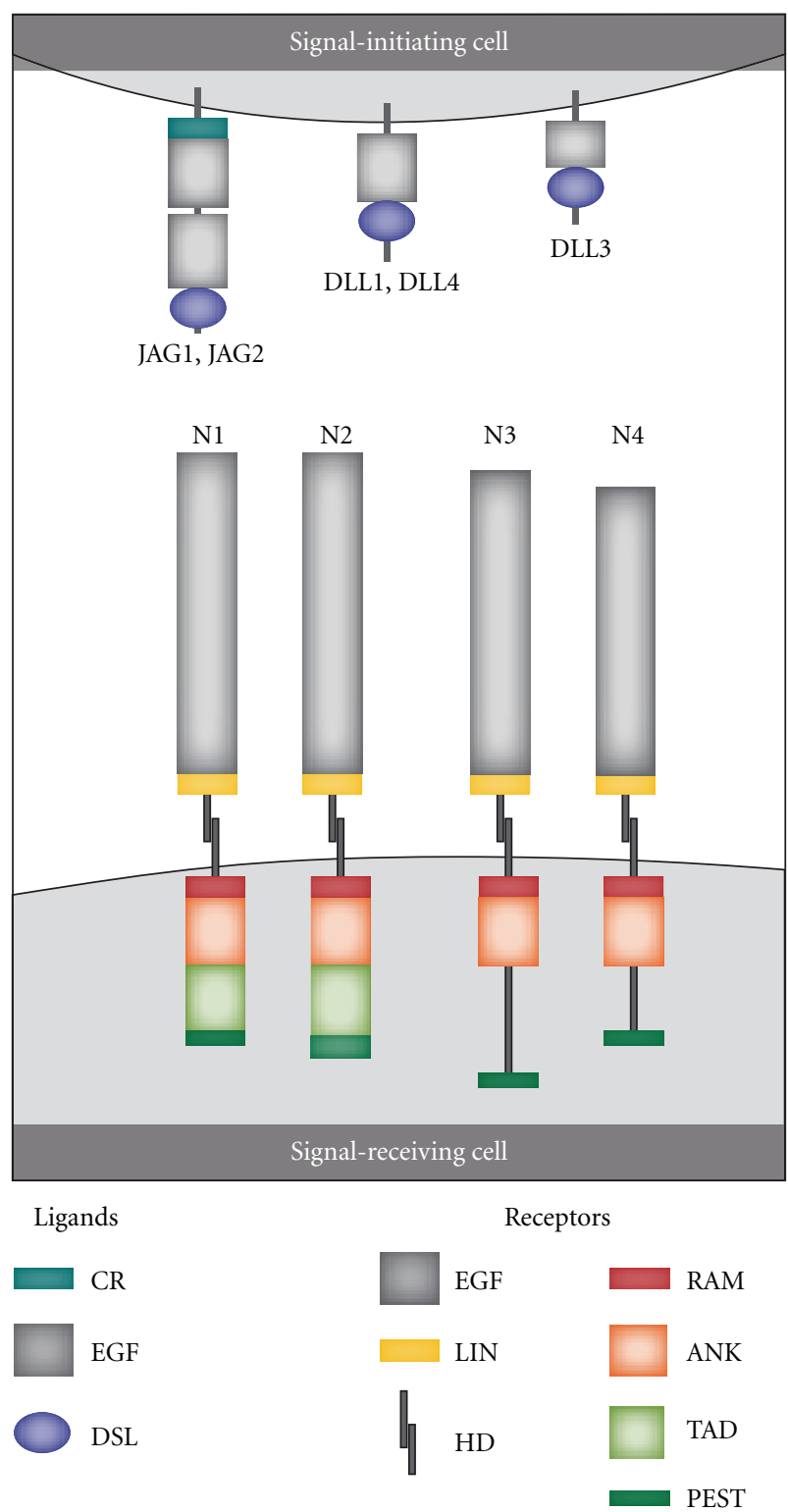

Figure 1: Notch receptors and their ligands. Signal-initiating cells express Notch ligands of the Delta-like (DLL1, DDL3, DLL4) or Jagged families (JAG1, JAG2). Common structural features of all ligands are the Epithelial growth factor-like (EGF) repeats and the distal amino-terminal domain called DSL (Delta, Serrate, and Lag-2). DSL is involved in receptor binding. Additionally, JAG1 and JAG2 contain a proximal cysteine-rich (CR) domain between the EGF-like repeats and the plasma membrane. In humans there are four heterodimeric Notch receptors (Notch1-4; N1-N4). The extracellular Notch receptor domain contains EGFlike repeats, a cysteine-rich LIN-12 repeats (LIN domain) that prevents ligand-independent activation, and the proximal heterodimerization domain (HD). The cytoplasmic domain contains an RBP-J-associated molecule (RAM) domain (closest to the cell membrane) followed by ankyrin repeats (ANK) that bind to the CSL (CBF1/RBP-J $\kappa /$ Suppressor of Hairless/LAG-1) transcription factor, a transactivation domain (TAD; only Notch 1 and 2), and a PEST (proline, glutamic acid, serine, threonine) sequence that is important for stabilization of the protein (adapted from [1]). factor (EGF-) like repeats followed by LIN domains that prevent ligand-independent activation. The transmembrane and cytoplasmic (NTM) subunit consists of the cytoplasmic RAM domain followed by ankyrine repeats that bind to the effector transcription factor CBF1, two nuclear localization signals, a transactivation domain that is present only in Notch1 and Notch2, and finally a PEST sequence involved in stabilization of the protein.

The five ligands also differ in their structure (Figure 1): the amino-terminal DSL domain (Delta, Serrate, and Lag2) which is involved in receptor binding is common to all ligands; this is followed by a variable number of EGF repeats; JAG1/2 contains an additional C-terminal cysteinerich domain (CR). The Delta ligands seem to have two activities: to trans-activate Notch in neighboring cells and to cis-inhibit Notch in its own cells [5]. Glycosylation of the extracellular Notch domain modulates ligand-initiated Notch signalling; for example, with regard to one experimental model DLL ligands were preferred over JAG ligands when the receptors contained N-Acetylglucosamine on the O-fucose residues in the EGF-like repeats $[1,6]$. Notch receptors seem to be promiscuous with regard to ligand binding, although it should be emphasized that the ligand specificity of the various receptors has not been characterized in detail. Notch1, Notch2, and Notch3 can all be activated by different ligands like DLL1, JAG1/2 [7, 8]; however, as mentioned, the ligand specificity of Notch1-4 has not been characterized in detail.

2.2. Canonical Intracellular Signalling. The first event in canonical Notch signalling (Figure 2) is ligand-receptor interaction with initiation of two successive proteolytic cleavages of the receptors (at sites S2 and S3 by ADAM family protease and the $\gamma$-secretase, resp.) and thereby the release of the Notch IntraCellular Domain (NICD). NICD translocates to the nucleus where it heterodimerizes with the DNAbinding transcription factor CBF1 (also named CSL or Rbpj) and recruits other coactivators, including mastermind-like proteins (MAML1-3) and the MED8-mediator transcription activation complex; this leads to induction of transcriptional expression of target genes. The Notch-associated gene expression profile will not depend on the receptor mediating the signal only since binding of different ligands to the same receptor will in some cases have different functional effects $[1,9]$.

2.3. Noncanonical Signalling. Noncanonical Notch signalling is well documented $[2,10]$, but less characterized than the canonical pathway. There are probably three types of noncanonical Notch signalling: Type I involves Notch ligation and translocation of activation signals independent of CBF1 (NICD-dependent but CBF1-independent); Type II involves activation of Notch target genes independent of S3 cleavage (NICD- and CBF1-independent); Type III involves CBF1-dependent gene activation without receptor cleavage and NICD release [10]. Several signalling pathways are involved, including Hedgehog, Jak/STAT, RTK, TGF, Wnt, PI3/Akt, mTor/Akt, JNK, MEK/ERK, and NFkB $[2,10]$. 


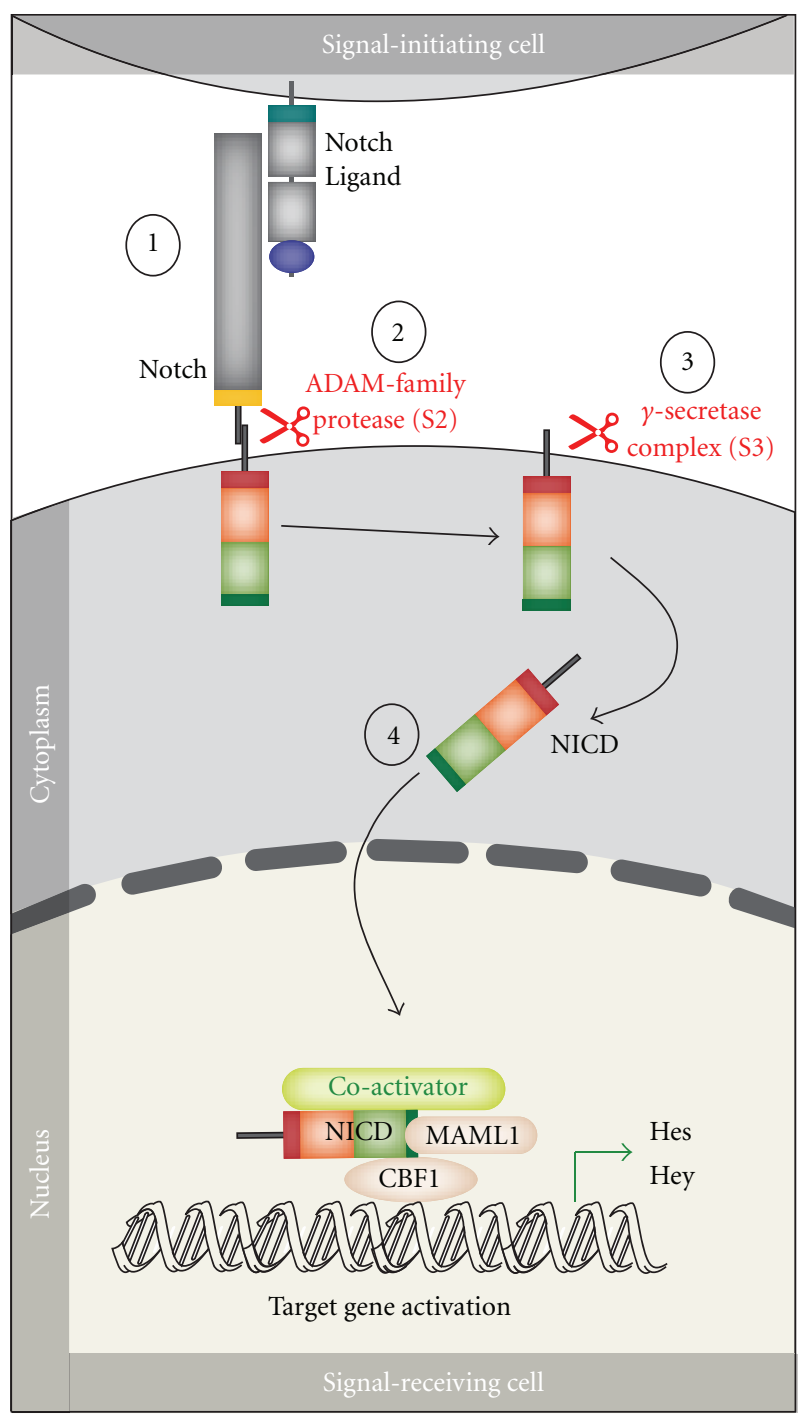

FIGURE 2: Notch canonical signalling pathway. The figure shows an overview of the canonical Notch signalling pathway (adapted from [4]). The signalling is initiated by ligand binding to Notch receptor (1). This binding initiates two subsequent proteolytic cleavages of the Notch receptor by the ADAM family protease (2) and the $\gamma$-secretase, respectively (3). The Notch IntraCellular Domain (NICD) is thereby released to the cytoplasm (4) and translocates to the nucleus where NICD heterodimerizes with the DNA-binding transcription factor CBF1 (also named CSL or Rbp-j). Additional coactivators are also recruited, including mastermind-like proteins (MAML1-3) ultimately leading to induction of transcriptional expression of downstream target genes, including those belonging to the Hes and Hey families.

Noncanonical Notch signalling seems important for maintenance of lineage-restricted hematopoietic progenitors, and several of the mediators involved in this signalling are in addition important in leukemogenesis as well as regulation of cellular immune responses. The noncanonical pathway thus represents a point of crosstalk between other intracellular signalling pathways.

\section{Notch and Hematopoietic Progenitors}

3.1. Notch in the Hematopoietic System. Notch1-mediated signals are essential for generation of definitive Hematopoietic stem cells (HSCs) during embryogenesis [11] though as described in more detail below, canonical Notch signalling seems to be dispensable for HSC maintenance in adults. HSCs reside primarily in the bone marrow in a complex microenvironment consisting of stromal cells, microvessels and extracellular matrix. These cells have the dual ability to self-renew as well as being able to give rise to all the cells in the hematopoietic system. Mainly HSCs are in a quiescent state; that is, the cells are in G0/G1 of the cell cycle and do not proliferate. An important factor in regulating the fate of HSCs in terms of HSC quiescence, self-renewal and differentiation, is the surrounding stem cell microenvironment, the so-called stem cell niche. HSCs have been shown to be in close proximity to cells lining the endosteum as well as near the specialised blood vessels in bone marrow called sinusoids [12].

3.2. The Osteoblastic Stem Cell Niche. The osteoblastic niche (also referred to as the endosteal niche) $[13,14]$ and the vascular niche $[12,15]$ create a supportive environment for stem cells. Notch signalling is thought to be a key signalling pathway involved in maintenance and expansion of the HSC pool. In addition, an important role of Notch signalling in osteoblast and osteoclast homeostasis was recently described $[16,17]$. Hematopoietic progenitor cells express Notch receptors and are exposed to Notch ligands in the bone marrow such as expression of JAG1 and DLL1 by osteoblasts $[13,18]$. In a study by Calvi et al., parathyroid hormone stimulation of osteoblasts in mice resulted in induced osteoblastic proliferation with increased expression of JAG1 and a Notch1-mediated expansion of HSCs $[13,19]$. These observations identified Notch as an important component of the stem cell niche that supports osteoblastic HSC regulation. However, further studies of osteoblastic regulation of HSCs via the Notch pathway have yielded conflicting results. Using serial transplantation studies, long-term reconstitution of HSCs was shown to be impaired after inhibition of Notch signalling [20]. In contrast, inactivation of neither JAG1 nor Notch1 impaired HSC maintenance in conditional knockout mouse models [21]. In a study by Maillard et al., Notch signalling was blocked by elimination of CBF1 and expression of dominant negative MAML mutants, and canonical Notch signalling was shown to be dispensable for the maintenance of long-term (LT) HSCs in vivo [22].

3.3. The Endothelial Stem Cell Niche. Endothelial cells promote HSC expansion and self-renewal in vitro and are shown to have an important role in engraftment of HSCs and reconstitution of hematopoiesis in vivo [23]. Inhibition of VEGFR2 signalling in sinusoidal endothelial cells impaired vascular recovery and hematopoietic reconstitution following irradiation in mice [23]. Thus, hematopoietic regeneration after myeloablation depends on vascular recovery and endothelial cell function, and Notch has been implicated in cell-cell 
interactions between HSCs and endothelial cells that regulate HSC function. In vivo, sinusoidal endothelial cells express Notch ligands JAG1 and JAG2 [24], and Notch-activated HSCs have been visualised in close proximity to the bone marrow vasculature [25]. A recent study used angiogenic models to demonstrate that Notch signalling via endothelial cells plays a role in regulation of HSCs in the vascular niche [24]. Increased expression of Notch ligand on endothelial cells after stimulation with soluble kit ligand stimulated the expansion of repopulating $\mathrm{CD} 34^{-} \mathrm{Flt}^{-}{ }^{-} \mathrm{Kit}^{+}$Lineage $^{-} \mathrm{Sca}{ }^{+}$ LT-HSCs at the expense of reducing differentiation, and serial transplantation assays demonstrated that these LTHSCs retained their self-renewal ability. Furthermore, in a coculture model, endothelial cells failed to expand HSCs derived from Notch1-/Notch2-deficient mice.

3.4. Notch as a Part of an Interactive Cell Signalling Network. Notch-initiated signalling is part of an interacting network of intracellular signalling pathways. The noncanonical activation of Notch signalling represents a crosstalk between Notch signalling and other intracellular signalling pathways (see above). Interactions between Notch and the Wnt pathway have been best characterized, but other interactions with various pathways have also been described.

(i) Wnt-initiated signalling is mediated through the downstream $\beta$-catenin [26]. The Wnt and Notch pathways seem to act in synergy to maintain the stem cell pool $[26,27]$. The crosstalk between these two pathways seems to occur at both the intracellular level and between cells in the stem cell niche. Firstly, members of the Wnt pathway regulate the expression of established Notch target genes, and inhibition of Wnt signalling affects the expression of both Wnt and Notch target genes $[20,28]$. Secondly, Wnt signalling can affect the expression of Notch1 as well as HoxB4 [29]. The HoxB4 transcription factor is important for HSC self-renewal and expansion by inducing the expression of genes preferentially expressed by HSCs and downregulating genes associated with myeloid differentiation $[30,31]$. Finally, an example of extrinsic crosstalk between these two pathways in the stem cell niche is the induced expression of Notch ligands by activated $\beta$-catenin in stromal cells which thereby induce-Notch-mediated intracellular signalling in adjacent HSCs [32].

(ii) Notch signalling becomes a part of a more extensive network through its crosstalk with the Wnt pathway that interacts with several other intracellular pathways [27], including (i) Hedgehog signalling [33], (ii) Prostaglandin E2 signalling; animal experiments suggest that this crosstalk is dependent on a protein kinase A-dependent mechanism that connects the pathways via $\beta$-catenin [34], (iii) Transforming growth factor- $\beta$ (TGF- $\beta$ ) and Bone morphogenic protein (BMP) signaling which targets the common intracellular mediator Smad4 that directly interacts with members of the Hox transcription factor family [26, 35], and (iv) Angiopoietin-1/Tie2 signalling which is also important in HSCs [36]; this signalling targets Cdh2 (N-cadherin) [37] that seems to activate $\beta$-catenin signalling through protein kinase B (Akt-) dependent mechanisms [38].

(iii) Hey2 is a transcription factor that seems to act downstream of Notch in primitive hematopoietic cells, and studies in zebrafish suggest that its expression is maintained by Hedgehog as well as Vascular endothelial growth factor signalling [39].

(iv) Several members of the NF- $\kappa \mathrm{B}$ family (including p65, p50, RelB, and c-Rel) are under transcriptional control by Notch-initiated signaling, and decreased levels were found in Notch-1 antisense transgenic (Notch-AS-Tg) mice [40]. NF- $\kappa \mathrm{B}$ is an important regulator of the expression of several chemokines, and Notch-initiated signalling may thereby affect chemotaxis and cell trafficking $[41,42]$.

(v) The Ets transcription factor Er71 seems to be a common downstream target both for the Wnt, Notch and BMP signalling pathways [43].

These observations clearly illustrate that Notch signalling is part of an extensive network of interacting pathways. These pathways are important for normal HSCs, and several of them are also important in the development of myeloid malignancies. Besides Notch signalling pathways (see below), the extensive network of interacting pathways includes the Wnt pathway [44, 45], Ang-1/Tie2 [46], HoxB4 [44, 47], Hedgehog signalling [44], BMP [35], NF- $\kappa$ B [48], and TGF$\beta /$ Smad4 $[35,49]$ signaling pathways. Thus, Notch signalling is a part of an extensive network involving several interacting pathways both in normal and leukemic hematopoietic cells.

\section{Notch Signalling in the Immune System}

4.1. The Role of Notch in $T$ Cell Development. Notch signalling is directly involved in the regulation of thymic $\mathrm{T}$ cell development with Notch1 acting as a key receptor responsible both for the lineage commitment and inhibition of other differentiation directions [1]. The DLL4 ligand is expressed by thymic epithelial cells and is essential for $\mathrm{T}$ lineage commitment [50] (Table 1). The $\alpha \beta \mathrm{T}$ cell development depends on Notch signalling, and transition through the $\beta$-selection checkpoint is then dependent on both Notch signalling [1] as well as CXCL12 ligation of CXCR4 with initiation of PI3K signalling [51]. Notch1 expression is downregulated after $\beta$-selection [1]. In contrast, the $\gamma \delta \mathrm{T}$ cell development seems less dependent on Notch signalling.

4.2. Effects of Notch on Peripheral T Cell Subsets. Naive T cells exit the thymus and migrate to the periphery where they mediate immune responses after antigenic recognition together with adequate costimulation. Activated naive $\mathrm{CD} 4^{+}$ $\mathrm{T}$ helper cells (Th0 cells) can differentiate towards Th1, Th2, Th9, Th17, and Th22 helper cells, or they may alternatively develop into induced regulatory $\mathrm{T}$ (iTreg) cells that act together with thymus-derived natural $\mathrm{T}$ regulatory 
TABLE 1: Notch ligand-receptor interaction: a summary of possible interactions involved in normal hematopoiesis, T cell development, and regulation of the peripheral $\mathrm{T}$ cell system.

\begin{tabular}{|c|c|c|c|c|}
\hline \multicolumn{2}{|c|}{ SIGNAL-INITIATING CELL } & \multicolumn{3}{|c|}{ SIGNAL-RECEIVING CELL } \\
\hline Cell type & Ligand & Cell type & Receptor & References \\
\hline Bone marrow stromal cells & & Bone marrow stem cells & & \\
\hline Osteoblasts (endosteal niche) & JAG1 & Sca- $1^{+}$, c-kit ${ }^{+}, \mathrm{Lin}^{-}$ & Notch1 & {$[13]$} \\
\hline (20) & JAG1, JAG2 & Sca- $1^{+}$, c-kit $^{+}, \mathrm{CD} 117^{+}$ & Notch1, Notch2 & {$[52]$} \\
\hline Endothelial cells (vascular niche) & JAG1, JAG2, DLL4, DLL1 & 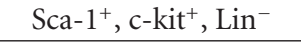 & Notch1, Notch2 & {$[24]$} \\
\hline Thymic epithelial cells (TECs) & & T cell progenitors & & \\
\hline TECs & DLL4 & Thymocytes & Notch1 & {$[1,50]$} \\
\hline Antigen-presenting cells & & Peripheral T cells & & \\
\hline APC & DLL1 & $\mathrm{Tc}$ & Notch1, Notch2 & {$[1]$} \\
\hline DC & DLL1, DLL4 & Th1 & Notch3 & {$[1,4,53]$} \\
\hline DC & JAG1, JAG2 & Th2 & Notch1, Notch2 & {$[1,4,53]$} \\
\hline APC & DLL1, DLL4 & Th17 & Notch & {$[1,54]$} \\
\hline $\mathrm{pDC}$ & DLL4 & Th1 IL- $10^{+}$ & Notch & {$[55]$} \\
\hline
\end{tabular}

Abbreviations: Delta-like (DLL); Jagged (JAG); Thymic epithelial cells (TECs); Antigen presenting cells (APC); Dendritic cells (DC); plasmacytoid DC (pDC); Cytotoxic T cells (Tc); Helper T cells (Th); Interleukin-10 (IL-10).

(nTreg) cells to inhibit immune responses. Activation of naive $\mathrm{CD}^{+} \mathrm{T}$ cells leads to the differentiation towards cytotoxic T lymphocytes (Tc, or also called CTLs). A detailed list of possible interactions between ligand-presenting and receptor-expressing cells involved in normal hematopoiesis, $\mathrm{T}$ cell development, and $\mathrm{T}$ cell activation is given in Table 1.

4.2.1. Tc Cells. The transcriptional regulator eomesodermin (Eomes) regulates the expression of perforin and granzyme $\mathrm{B}$ in $\mathrm{CD}^{+}$cytotoxic T cells [56]. Notch 1 seems to directly regulate expression of Eomes as well as perforin and Granzyme $\mathrm{B}$ by binding to their promoters, and $\gamma$-secretase inhibitors (GSIs) thereby attenuate in vitro $\mathrm{T}$ cell cytotoxicity. In addition, Notch2-ICD seems to cooperate with CREB1 in the regulation of granzyme B expression [57].

4.2.2. Th1 and Th2 Cells. Th1 cells produce IFN $\gamma$ while Th2 cells produce IL-4, IL-5, and IL-13 as their signature cytokines. Jagged ligands expressed by APCs are important for Th2 differentiation whereas DLL ligands (DLL1 and/or DLL4) seem to promote Th1 and inhibit Th2 differentiation, but the additional molecular events in this differentiation have not been characterized [1]. Thus, it is not known which Notch receptors mediate the DLL-induced Th1 cell differentiation signal. Although canonical Notch signalling does not seem to be essential [1], Notch3 signalling is possibly also involved in Th1 differentiation [58]. On the other hand, Th2 cell differentiation seems to involve CBF1 and IL-4, as well as the Th2-specific transcription factor Gata3 that is a Notch target gene [58].

4.2.3. Th17 Cells. These cells represent a proinflammatory subset distinct from Th1 cells; their signature cytokines are IL-17A, IL-21, and IL-22, and they express the Th17-specific transcription factor ROR $\gamma$. DLL ligands might play a role in the generation of Th17 cells [1], and recent in vitro studies
[54] suggest that DLL4 inhibits Th2 cytokine production, contributes to Th17 differentiation, and upregulates RORc expression. Both the ROR $c$ and IL-17 gene promoters then seem to be direct targets for Notch-initiated signalling.

4.2.4. Treg Cells. Both natural (nTreg) and peripherally induced Treg (iTreg) cells are important for downregulation of immune responses. FoxP3 is a Treg-specific transcription factor, and the cells typically release IL-10. Notch ligands (usually the Jagged family) increase Treg cell differentiation in vitro $[1,4,59,60]$, but this differentiation is not Notchdependent because Notch loss-of-function mutant mice do not lack Treg cells [1]. Notch1 signalling seems to contribute to the FoxP3 expression [61], and Notch3 receptors are increased on murine $\mathrm{CD} 4^{+} \mathrm{CD} 25^{+}$Treg cells [62]; exposure to JAG2-overexpressing hematopoietic progenitors seems to increase the expression of Notch3 and FoxP3 in Treg cells [63].

4.3. Notch and Autoimmunity. There are few reports of Notch in human autoimmune diseases. Recently Jiao et al. [64] reported increased expression of Notch2/3/4 in Th cells from patients with active rheumatoid arthritis, and the increased expression of Notch3 was mainly detected in activated T cells. These patients also show increased nuclear translocation of NICD in Th cells as well as increased expression of the Notch target gene HES-1 [64]. Another recent study [65] reported increased expression of Notch1/3 and decreased Notch2 together with downregulated DLL1 among peripheral blood mononuclear cells from patients with autoimmune thrombocytopenia. Finally, Sodsai et al. [66] suggest that defective Notch1 upregulation during $\mathrm{T}$ cell activation is important for increased disease activity in patients with systemic lupus erythematosus. However, it should be emphasized that a major part of these studies only included a description of Notch/Notch ligand expression in immunocompetent cells; it is therefore difficult to judge 
whether this altered expression is directly involved in disease development/progression or only represents secondary (innocent bystander or secondary) effects that may not be clinically important.

The importance of Notch signalling in autoimmune diseases has been investigated more in detail in murine models of autoimmune disorders, and these results are summarized in Table 2 . The contribution of Notch signalling has especially been investigated in experimental autoimmune encephalomyelitis (EAE), an experimental model of multiple sclerosis. Th1 and Th17 cells are important for the development of this disease, and inhibitions of Notch3, $\gamma$-secretase, or DLL1 inhibit proinflammatory Th1/Th17 responses and improve disease symptoms. In contrast, DLL2initiated signalling increases symptoms whereas JAG1 results in improvement. Furthermore, Notch1-induced signalling also seems important for the development of autoimmunity in other organs, but these effects seem to differ depending on the experimental model. Finally, Notch-induced signalling with induction of Treg cells can inhibit the development of autoimmune diabetes in various disease models. It should be emphasized that several of these conclusions are based on the observed effects when using specific Notch inhibition in the experimental models (like specific neutralizing antibodies) as described in detail in Table 2; these effects of specific inhibitors demonstrate that Notch-initiated signalling is directly involved in the regulation of experimental murine autoimmunity.

Many clinical and laboratory features of GVHD, especially in its chronic form, resemble those of autoimmune diseases, and the pathophysiological mechanisms also seem to show similarities $[72,73]$. Autoimmune phenomena can be seen after both auto- and allotransplantation, and the most common manifestations seem to be thyroid disease and autoimmune cytopenias. Certain manifestations of GVHD have been postulated to represent a specific loss of tolerance to self structures. Taken together, these observations suggest that the role of Notch signalling in autoimmune diseases is relevant also for development of GVHD.

\section{Immune Reconstitution after Stem Cell Transplantation}

Immunological reconstitution after stem cell transplantation has been extensively reviewed previously [74-78], and the most important observations both in allogeneic and autologous transplantation are (i) early lymphoid reconstitution is associated with a decreased risk of relapse, suggesting that antileukemic immune reactivity is mediated early after transplantation [79-82] and (ii) a long-lasting quantitative CD4 $\mathrm{T}$ cell defect can persist for several months post transplant $[75,76,78]$.

The quantitative $\mathrm{CD} 4^{+} \mathrm{T}$ cell defect after allotransplantation may last for several months, but early normalization seems more common after reduced intensity conditioning [78]. Infusion of a high number of $\mathrm{CD}^{+} \mathrm{T}$ cells and Natural Killer (NK) $\mathrm{T}$ cells seems to be associated with a better prognosis [83], an observation supporting the hypothesis that early antileukemic immune reactivity is important. Recovery of dendritic cells occurs more slowly [84], and an abnormal ratio between various dendritic cell subsets may persist for months after transplantation [84]. Low dendritic cell counts one month post transplant also seem to be an independent adverse prognostic factor for the overall survival [85].

In autotransplanted patients the immunological reconstitution differs between patients receiving peripheral blood and bone marrow autografts [86]. Mobilized stem cells are now most commonly used, and during the first posttransplant months the patients generally show early recovery of $\mathrm{CD}^{+} \mathrm{T}$ cells, $\mathrm{CD} 14^{+}$monocytes, and $\mathrm{CD} 56^{+} \mathrm{NK}$ cells [86-88]. Circulating dendritic cells are usually normalized relatively early, although differences in dendritic cell subset composition may persist for several months also in these patients [88]. The T cell defect is detected after 6 months for most of these patients and may last for more than a year [87], and it is mainly due to reduced naive $\mathrm{CD} 3^{+} \mathrm{CD} 4^{+} \mathrm{CD} 45 \mathrm{RA}^{+}$ $\mathrm{T}$ cells, but reduced $\mathrm{CD} 8^{+}$naive $\mathrm{T}$ cells can also be seen $[87,88]$.

\section{Notch in Hematological Malignancies}

6.1. T-Lineage Acute Lymphoblastic Leukemia. ALL is characterized by accumulation of immature lymphoblast of either $\mathrm{B}$ or $\mathrm{T}$ cell lineage origin in bone marrow and eventually other lymphoid organs. T-ALL accounts for approximately one third of all cases [89]. Notch involvement in T-ALL was first described in patients with the rare $t(7 ; 9)$ ( $q 43 ; q 34.3)$ translocation that leads to the expression of a cytoplasmic form of the Notch1 receptor with constitutive activity [90]. However, the most common Notch abnormality in T-ALL is mutations in the Notch1 alleles that result in constitutive activation of the pathway; this is seen in more than half of the patients [91]. These Notch1 mutations are located at specific hotspots and affect critical negative regulatory elements of the protein. The molecular mechanisms by which aberrant Notch1 signalling contributes to T-cell transformation are not yet fully understood. Oncogenic Notch1 probably cooperates with oncogenic transcription factors such as c-Myc [92], E2A-PBX [93], and Ikaros [94], but the aberrant Notch1 signalling is not sufficient for leukemic transformation [95]. Observations in animal models suggest that even nonmutational Notch1 activation contributes to leukemogenesis [96], probably through activation of c-Myc that is a direct downstream target of Notch1 [92]. Finally, the prognostic impact of Notch1 mutations was demonstrated in recent clinical studies where the mutations were associated with good prognosis both in children [97] and adults [98].

6.2. Acute Myeloid Leukemia. The prevalence of Notch mutation in AML is probably less than 5\% [99, 100], and Notch ligation in AML cells has diverse or only minor effects [101]. AML cells seem to express JAG1, Notch1 and Notch2 [102-104]. In hematopoiesis, Notch1, drives myeloid differentiation through the expression of transcriptional factor PU.1. Results obtained from Chen et al. in [104] 
TABLE 2: Therapeutic targeting of Notch in murine autoimmunity in vivo.

\begin{tabular}{|c|c|c|}
\hline Disease and intervention & Therapeutic effect & References \\
\hline \multicolumn{3}{|c|}{ Experimental autoimmune encephalomyelitis (EAE; model of multiple sclerosis) } \\
\hline$\gamma$-secretase inhibitor & $\begin{array}{l}\text { Inhibition of disease-associated Th1 responses and } \\
\text { improvement of symptoms }\end{array}$ & {$[4,58,67]$} \\
\hline Notch1 neutralizing antibodies & No effect on Th1 and Th17 responses & {$[4,58]$} \\
\hline Notch3 neutralizing antibodies & $\begin{array}{l}\text { Decreased Th1 and Th17 responses, inhibition of the ability of } \\
\text { myelin-primed T cells to transfer the disease }\end{array}$ & {$[4,58]$} \\
\hline DLL1 neutralizing antibodies & Reduced Th1 responses and EAE symptoms & {$[4,68]$} \\
\hline Activating DLL1-Fc fusion protein & Increased Th1 responses and EAE symptoms & {$[4,68]$} \\
\hline Neutralizing JAG1 antibodies & EAE disease progression & {$[4,68]$} \\
\hline Activating JAG1-Fc fusion protein & Improvement of EAE symptoms & {$[4,68]$} \\
\hline
\end{tabular}

Experimental hepatitis

$\gamma$-secretase inhibitor

Murine diabetes

Lck-Notch3-IC transgenic mice

Exposure to JAG2-expressing hematopoietic progenitor cells

Multiorgan autoimmune disease

Loss of functional mutation in the Itch ubiquitin ligase
Reduced Notch1 signalling and FoxP3 expression, spontaneous hepatic lymphocyte infiltration consistent with autoimmune hepatitis (C57BL/6 mice)

Up regulation of the generation and function of $\mathrm{CD} 4^{+} \mathrm{CD} 25^{+}$

Treg. The mice failed to develop streptozotocin-induced autoimmune diabetes. Adoptive transfer of the lck-Notch3-IC transgenic $\mathrm{CD}^{+}$cells to wild-type recipients prevented the progression of the disease.

Activation of Notch3 signalling with increased Treg proliferation and prevention of diabetes in NOD mice.

This ligase is involved in Notch1 degradation; homozygous mice develop an autoimmune-like disease mainly affecting lungs, skin, and lymphoid organs.

Abbreviations: Experimental autoimmune encephalomyelitis (EAE), Delta-like (DLL), Jagged (JAG), Helper T cells (Th).

show that the Notch1 gene and protein expression were decreased in human AML samples in comparison with normal hematopoietic stem cells. This decrease of Notch1 expression was associated with a concordant downregulation in PU.1, suggestive of impeded PU.1-mediated myeloid signalling and thus contributing to AML leukemogenesis [104]. However, gene expression profiling of primary human AML cells has identified a subgroup of patients with recurring mutations in Notch $[105,106]$; the expression profile of these patients seems to be mainly determined by silencing of the CEBPA gene through promoter hypermethylation [106]. The CEBPA gene encodes for the transcription factor CCAAT/enhancer-binding protein alpha (C/EBPalfa); this gene is mutated in approximately $10 \%$ of AML cases [107]. AML cells with silenced CEBPA gene and Notch mutations cluster together [106].

6.3. Chronic Lymphocytic Leukemia. Chronic lymphocytic leukemia (CLL) is characterized by detection of malignant $\mathrm{CD}^{+} \mathrm{CD} 19^{+} \mathrm{B}$ cells in blood, bone marrow, and eventually other lymphoid organs. Several recent studies suggest that the Notch system is important also in B-CLL. Firstly, B-CLL cells express high levels of Notch2 that regulate the expression of antiapoptotic CD23a [108]. Secondly, Notch $1 / 2$ and the ligands JAG1/2 are also constitutively expressed in B-CLL [109] and are then associated with resistance to apoptosis [109]. Upregulation of Notch1 is observed during treatment with the MDM2/p53 inhibitor Nutlin-3 and possibly represents a feedback mechanism involved in restrain of the Nutlin-3 effects [110].

\section{Possible Strategies for Notch Targeting in Patients Treated with Stem Cell Transplantation}

7.1. Therapeutic Tools for Inhibition of Canonical Notch Signalling. An overview of possible therapeutic tools is given in Table 3. The tools include ligands, agonistic and antagonistic antibodies, stimulatory fusion proteins, and inhibitors of intracellular signalling. Inhibition of the $\gamma$ secretase activity with general downregulation of Notch signalling has been used in experimental in vitro studies [111]. Unless NICD is translocated to the nucleus, the NICD form of Notch is ubiquitinated and thereafter degraded by the proteasomes; and proteasomal inhibitors may thus enhance Notch signalling. Various proteasomal inhibitors are now used in the treatment of hematologic malignancies, and they are also tried as immunosuppressive agents [112-115], but it is not known whether inhibition of Notch signalling contributes to their clinical effects.

The results summarized in Table 3 suggest that if a detailed characterization of the immune system is available, 
TABle 3: Potential molecular tools for targeting of Notch signalling.

\begin{tabular}{|c|c|c|}
\hline Molecular tool & Observations in clinical or experimental studies & References \\
\hline \multicolumn{3}{|l|}{ Natural receptor ligands } \\
\hline $\begin{array}{l}\text { JAG2-expressing hematopoietic } \\
\text { progenitor cells }\end{array}$ & $\begin{array}{l}\text { Activation of Notch3 signalling with increased Treg } \\
\text { proliferation and prevention of diabetes in NOD mice. }\end{array}$ & {$[63]$} \\
\hline $\begin{array}{l}\text { Fusion proteins of natural ligands and } \\
\text { Fc-Ig }\end{array}$ & $\begin{array}{l}\text { DLL1-IgG-Fc has been used for expansion of human umbilical } \\
\text { cord stem cell expansion; cells caused no unexpected toxicity } \\
\text { and contributed to long-term engraftment. Could be used for } \\
\text { transplantation. }\end{array}$ & {$[116]$} \\
\hline JAG1- and DLL2-Fc fusion proteins & $\begin{array}{l}\text { Both types of fusion proteins have shown immunomodulatory } \\
\text { effects in experimental murine disease models. }\end{array}$ & {$[4,68]$} \\
\hline \multicolumn{3}{|l|}{ Receptor-or ligand-directed antibodies } \\
\hline Agonistic antibodies & $\begin{array}{l}\text { Agonistic antibodies have been identified for their reactivity } \\
\text { against Notch2 or Notch3. }\end{array}$ & {$[117,118]$} \\
\hline $\begin{array}{l}\text { Antagonistic antibodies directed against } \\
\text { Notch }\end{array}$ & $\begin{array}{l}\text { Several antagonistic Notch1-, Notch2- or Notch3-directed } \\
\text { antibodies have been tested in vitro and in vivo. }\end{array}$ & $\begin{array}{l}{[4,58,117} \\
119,120]\end{array}$ \\
\hline $\begin{array}{l}\text { Antagonistic antibodies directed against } \\
\text { Notch ligands }\end{array}$ & $\begin{array}{l}\text { Both DLL- and JAG1- specific antibodies show } \\
\text { immunomodulatory effects in murine disease models. }\end{array}$ & {$[4,68]$} \\
\hline DLL1 neutralizing antibodies & Reduced Th1 responses and improvement of EAE symptoms. & {$[4,68]$} \\
\hline DLL4 neutralizing antibodies & $\begin{array}{l}\text { In CSC-driven colon and breast xenograft models, anti-human } \\
\text { DLL4-blocking antibodies inhibited tumour growth and } \\
\text { reduced tumour-initiating cell frequencies. }\end{array}$ & {$[121]$} \\
\hline $\begin{array}{l}\text { Antibodies that inhibit the } \\
\text { transcription-regulating complex }\end{array}$ & $\begin{array}{l}\text { Development of such antibodies could inhibit parts of the } \\
\text { Notch-initiating effects and possibly limit the toxicity. }\end{array}$ & {$[122]$} \\
\hline Activating JAG1-Fc fusion protein & Improvement of EAE symptoms. & {$[4,68]$} \\
\hline Activating DLL2-Fc fusion protein & Increased Th1 responses and progression of EAE symptoms. & {$[4,68]$} \\
\hline \multicolumn{3}{|l|}{ Inhibition of intracellular signalling } \\
\hline$\gamma$-secretase inhibitor & $\begin{array}{c}\text { Reduced Notch1 signalling and FoxP3 expression in Treg cells in } \\
\text { murine disease models. }\end{array}$ & {$[58,61,67]$} \\
\hline Proteasome inhibitors & Inhibition of noncanonical Notch signalling. & $\begin{array}{l}{[2,10,123,} \\
124]\end{array}$ \\
\hline $\begin{array}{l}\text { Inhibition of the PI3K-Akt-mTOR } \\
\text { pathway }\end{array}$ & Inhibition of noncanonical Notch signalling. & {$[2,10,48]$} \\
\hline $\begin{array}{l}\text { Peptide that inhibits assembly of the } \\
\text { transcription-regulating complex }\end{array}$ & $\begin{array}{l}\text { The small hydrocarbond-staple peptide SAHM1 inhibits Notch } \\
\text { signalling in vitro. }\end{array}$ & {$[122]$} \\
\hline
\end{tabular}

Abbreviations: Experimental autoimmune encephalomyelitis (EAE), Delta-like (DLL), Jagged (JAG), Helper T cells (Th), Cancer stem cell (CSC).

it would be possible to design therapeutic strategies based on stimulation or inhibition of selected Notch-mediated effects. Especially in allograft recipients, Notch inhibition may offer the opportunity to combine immunosuppressive GVHD prophylaxis with direct antileukemic effects.

\subsection{Notch-Driven Stem Cell Expansion Effects on Posttrans-} plant Myeloid Reconstitution. The delayed hematopoietic stem cell engraftment commonly seen after cord blood transplantation is probably due to an inadequate numbers of progenitor cells in the graft [116]. In a recent phase I clinical trial, $\mathrm{CD} 34^{+}$cord blood cells were cultured ex vivo with the extracellular DLL1 domain fused to the Fc domain of human IgG. After 16 days and following myeloablative conditioning, the expanded cells were transplanted together with an unmanipulated allograft. No unexpected toxicity was observed, and the patients showed early myeloid reconstitution with a shortened time until peripheral blood neutrophil counts $\geq 0.5 \times 10^{9} / \mathrm{L}$ (16 days compared with 26 days for the controls). In four of these patients, the neutrophil reconstitution was attained at a time when at least $80 \%$ of the cells were derived from the manipulated grafts, and for two patients, long-term persistence of these cells was documented after 180 and 240 days. For other patients, persisting cells were derived from the unmanipulated graft. Thus, targeting of Notch can be used for ex vivo stem cell expansion of allogeneic stem cells. Whether a similar methodological approach can be used for ex vivo expansion of autologous stem cells in poor mobilizers has not been investigated, but the use of a CXCR4 antagonist would at present be the first alternative for such patients [125]. Another possible therapeutic strategy may be in vivo expansion of stem and progenitor cells by administration of the Delta1-IgG preparation.

7.3. Notch Targeting and Posttransplant Lymphoid Reconstitution. Early lymphoid reconstitution after stem cell transplantation is associated with decreased relapse risk in several 
hematological malignancies [126]. The study by Delaney et al. [116] demonstrated that ex vivo stem cell expansion reduced the time until neutrophil reconstitution, but the manipulated grafts did not contain $\mathrm{T}$ cells, and long-term $\mathrm{T}$ cell engraftment was always derived from the unmanipulated grafts (see above). Notch-induced signalling is also important for T lymphopoiesis, but it is not known whether alternative ex vivo or in vivo strategies for Notch targeting can be used to increase lymphopoiesis and thereby shorten the time until lymphoid reconstitution and thereby shorten the posttransplant CD4 defect. Such a strategy may become useful in autotransplanted patients to increase posttransplant antileukemic $\mathrm{T}$ cell reactivity, whereas it would be more difficult to use in allotransplanted patients with the risk of severe and potentially lethal GVHD.

\subsection{Notch Targeting of Malignant Hematopoietic Cells-} The Initial Clinical Experience. Allogeneic and autologous stem cell transplantation is mainly used in the treatment of hematologic malignancies, and Notch signalling seems important in these diseases, especially T-ALL (see above). Inhibitors of the $\gamma$-secretase activity have been developed, but the initial clinical Phase I studies in T-ALL patients showed a low efficiency and severe gastrointestinal toxicity [127]. Several other Notch-targeting drugs are now being developed for use in clinical phase 1-2 trials, and one of them has also been investigated in a phase 3 trial [128]. These agents are mainly $\gamma$-secretase inhibitors that are tried in the treatment of various cancers. Whether these inhibitors will have an acceptable toxicity and higher efficiency has to be addressed in future studies.

\subsection{Targeting Noncanonical Notch Signalling-Possible Mech-} anisms for the Antileukemic Effects of Several Targeted Therapies. Several drugs may affect the expression of Notchtargeted genes through inhibition of the noncanonical pathways such as HSP90, HDAC, PI3K/Akt/mTOR, and proteasomal inhibitors $[2,10]$. Some of these drugs may have combined effects; for example, proteasomal inhibitors may alter noncanonical signalling through $\mathrm{NF} \kappa \mathrm{B}$ inhibition together with decreased degradation of the NICD form involved in canonical signalling. Furthermore, specific PI3K inhibitors are now evaluated in clinical studies [129]. The PI3K-Akt pathway is upstream to mTOR, and the mTOR inhibitor rapamycin is used for immunosuppression after allotransplantation and is also being investigated as an anticancer agent in hematologic malignancies. Thus, Notch inhibition may contribute to the efficiency of several new anticancer and/or immunosuppressive-targeted therapeutics.

7.6. Notch Targeting in Stem Cell Recipients: Immunosuppression versus Immunostimulation. As can be seen from Table 2, Notch targeting can be used both for immunostimulation and immunosuppression in experimental autoimmunity, and these observations may be relevant also for human GVHD [72, 73]. Thus, Notch signalling seems important both for $\mathrm{T}$ lymphopoiesis and for regulation of the peripheral
T cell system. Notch agonists may thus become useful to enhance $\mathrm{T}$ cell reconstitution after both allogeneic and autologous stem cell transplantation. Early lymphoid reconstitution is then associated with decreased risk of cancer relapse, and earlier $\mathrm{T}$ cell reconstitution would possibly further reduce the relapse risk. $\mathrm{T}$ cell defects are in addition associated with an increase of severe opportunistic infections especially in allotransplant recipients $[130,131]$, and early reconstitution may also reduce this risk. On the other hand, enhancement of $\mathrm{T}$ cell reconstitution after allotransplantation has to be balanced against a possible risk of inducing severe and potentially lethal GVHD.

A second possibility could be to use Notch-targeting therapy to modulate the function of peripheral $\mathrm{T}$ cells. Immunostimulatory agonists could then be used to enhance antileukemic immune reactivity after autologous stem cell transplantation. Clinical studies have demonstrated that antileukemic $\mathrm{T}$ cells can be detected in autotransplanted leukemia patients and that this reactivity can possibly be enhanced by vaccination therapy [126]. Immunostimulatory Notch targeting may then increase this antileukemic reactivity and possibly increase the efficiency of anticancer vaccines.

A third strategy is to consider immunomodulatory strategies to reduce the risk of severe GVHD after allotransplantation. Yvon et al. [132] overexpressed the JAG1 ligand in alloantigen-presenting $\mathrm{B}$ cells and observed induction of Treg cells from CD45-RA ${ }^{+} \mathrm{T}$ cells; these allospecific Treg cells caused a specific inhibition of proliferative and cytotoxic $\mathrm{T}$ cell responses against the priming alloantigens. Thus, Notch agonists may be used to induce specific tolerance against alloantigens, and both ex vivo generation of immunoregulatory cells and in vivo administration of agonists should be considered. An alternative would be to use Notch inhibition for suppression of effector $\mathrm{T}$ cells (see Table 2). However, the use of Notch inhibition in targeting the peripheral $\mathrm{T}$ cell system seems less attractive because this approach may interfere with lymphoid reconstitution and aggravates the posttransplant $\mathrm{T}$ cell defects (see above).

7.7. Mesenchymal Stromal Cells. Multipotent mesenchymal stromal cells (MSCs), also called mesenchymal stem cells, are able to differentiate into a variety of cell types including osteoblasts, chondrocytes, and adipocytes [133]. These cells are important components of the bone marrow HSC niche and can support HSC maintenance and engraftment [134]. Intriguingly, MSCs have also been shown to have immunomodulatory properties which are of value in a clinical setting with regard to treatment of GVHD after hematopoietic stem cell transplantation (HSCT). Moreover, cotransplantation of HSCs and MSCs can facilitate hematopoietic engraftment and was shown to accelerate lymphocyte recovery in clinical HSCTs [135]. The exact mechanisms of how MSCs contribute to hematopoietic reconstitution remain unclear though both immunomodulatory effects as well as effects on HSC self-renewal capacity are assumed and Notch signalling has been implicated in these effects. Studies of Notch function have 
revealed that Notch signalling affects various differentiation capabilities of MSC, including differentiation in direction of osteoblasts [17, 136, 137]. Notch signalling in bone marrow is suggested to maintain a pool of mesenchymal progenitors by suppressing osteoblast differentiation [16]. In addition, Notch signalling has been identified as a possible pathway involved in osteogenic differentiation of MSCs induced by soluble mediators derived from endothelial cells [138].

The infusion of MSCs has been tried in the treatment of GVHD. There seems to be a consensus that these cells are immunomodulatory, but the initial clinical studies have shown conflicting results with regard to the efficiency of MSC in the treatment of GVHD [139141]. Human bone marrow-derived MSCs were found to express high levels of functionally active toll-like receptors (TLR) 3 and 4, and these cells had an immunosuppressive effect on T-cell proliferation after ligation of either TLR3 or TLR4. Suppression of T-cell activation was inhibited by neutralization of JAG1 and inhibition of $\gamma$-secretase activity, thus implying a role of impaired Notch receptor signalling in T cells [142]. Additional mechanisms possibly involved in MSC-induced immunomodulation could be interactions with the NK cell system, inhibition of dendritic cell differentiation, or modulation of the humoral system [139].

To conclude, even though additional studies are definitely needed, these studies suggest that Notch signalling may be important both for the development of supportive cells in stem cell niches and for the immunomodulatory/GVHDsuppressing effect of the MSC.

7.8. Concluding Remarks. The Notch ligand/receptor system is important for (i) development and regulation of the $\mathrm{T}$ cell system and (ii) regulation of normal as well as leukemic hematopoiesis. The final biological effects of Notch targeting in stem cell recipients are difficult to predict, and depend both on the involved ligand(s) and receptors, and signalling through the canonical intracellular pathway is modulated by noncanonical signalling. The interactions between Notchinitiated signalling and several other intracellular signalling pathways further make it difficult to predict the final effect of Notch-targeted therapy. Pharmacological tools for targeting of Notch-mediated signalling are now being developed. However, because the effects of Notch-targeted therapy are difficult to predict a more detailed study of the post-transplant hematopoiesis as well as the $\mathrm{T}$ cell system is necessary before clinical studies of these agents in transplant recipients can be designed. However, such studies should be encouraged because Notch targeting may represent a unique possibility to combine enhancement of reconstitution, immunomodulation, and direct anticancer treatment.

\section{Acknowledgment}

The scientific work of the authors is supported by the Norwegian Cancer Society and Helse-Vest.

\section{References}

[1] F. Radtke, N. Fasnacht, and H. R. MacDonald, "Notch signaling in the immune system," Immunity, vol. 32, no. 1, pp. 14-27, 2010.

[2] C. Talora, A. F. Campese, D. Bellavia et al., "Notch signaling and diseases: an evolutionary journey from a simple beginning to complex outcomes," Biochimica et Biophysica Acta, vol. 1782, no. 9, pp. 489-497, 2008.

[3] A. R. Sandy and I. Maillard, "Notch signaling in the hematopoietic system," Expert Opinion on Biological Therapy, vol. 9, no. 11, pp. 1383-1398, 2009.

[5] D. Sprinzak, A. Lakhanpal, L. Lebon et al., "Cis-interactions between Notch and Delta generate mutually exclusive signalling states," Nature, vol. 465, no. 7294, pp. 86-90, 2010.

[6] N. Haines and K. D. Irvine, "Glycosylation regulates Notch signalling," Nature Reviews Molecular Cell Biology, vol. 4, no. 10, pp. 786-797, 2003.

[7] K. Shimizu, S. Chiba, N. Hosoya et al., "Binding of Delta1, Jagged1, and Jagged2 to Notch2 rapidly induces cleavage, nuclear translocation, and hyperphosphorylation of Notch2," Molecular and Cellular Biology, vol. 20, no. 18, pp. 6913-6922, 2000.

[8] K. Shimizu, S. Chiba, T. Saito, K. Kumano, and H. Hirai, "Physical interaction of Delta1, Jagged1, and Jagged2 with Notch1 and Notch3 receptors," Biochemical and Biophysical Research Communications, vol. 276, no. 1, pp. 385-389, 2000.

[4] D. Amsen, A. Antov, and R. A. Flavell, "The different faces of Notch in T-helper-cell differentiation," Nature Reviews Immunology, vol. 9, no. 2, pp. 116-124, 2009.

[9] I. Van de Walle, M. De Smet, E. Waegemans et al., "The Serrate-like ligand Jagged2 acts as a Delta-like Notch ligand during hematopoietic cell fate decisions," Submitted.

[10] R. Sanalkumar, S. B. Dhanesh, and J. James, "Non-canonical activation of Notch signaling/target genes in vertebrates," Cellular and Molecular Life Sciences, vol. 67, no. 17, pp. 29572968, 2010.

[11] À. Robert-Moreno, L. Espinosa, J. L. de la Pompa, and A. Bigas, "RBPjא-dependent Notch function regulates Gata2 and is essential for the formation of intra-embryonic hematopoietic cells," Development, vol. 132, no. 5, pp. 11171126, 2005 .

[12] M. J. Kiel, O. H. Yilmaz, T. Iwashita, O. H. Yilmaz, C. Terhorst, and S. J. Morrison, "SLAM family receptors distinguish hematopoietic stem and progenitor cells and reveal endothelial niches for stem cells," Cell, vol. 121, no. 7, pp. 1109-1121, 2005.

[13] L. M. Calvi, G. B. Adams, K. W. Weibrecht et al., "Osteoblastic cells regulate the haematopoietic stem cell niche," Nature, vol. 425, no. 6960, pp. 841-846, 2003.

[14] D. Visnjic, Z. Kalajzic, D. W. Rowe, V. Katavic, J. Lorenzo, and H. L. Aguila, "Hematopoiesis is severely altered in mice with an induced osteoblast deficiency," Blood, vol. 103, no. 9, pp. 3258-3264, 2004.

[15] H.-G. Kopp, S. T. Avecilla, A. T. Hooper, and S. Rafii, “The bone marrow vascular niche: home of HSC differentiation and mobilization," Physiology, vol. 20, no. 5, pp. 349-356, 2005.

[16] M. J. Hilton, X. Tu, X. Wu et al., "Notch signaling maintains bone marrow mesenchymal progenitors by suppressing osteoblast differentiation," Nature Medicine, vol. 14, no. 3, pp. 306-314, 2008. 
[17] F. Engin, Z. Yao, T. Yang et al., "Dimorphic effects of Notch signaling in bone homeostasis," Nature Medicine, vol. 14, no. 3, pp. 299-305, 2008.

[18] F. N. Karanu, B. Murdoch, L. Gallacher et al., "The Notch ligand Jagged-1 represents a novel growth factor of human hematopoietic stem cells," Journal of Experimental Medicine, vol. 192, no. 9, pp. 1365-1372, 2000.

[19] J. Zhang, C. Niu, L. Ye et al., "Identification of the haematopoietic stem cell niche and control of the niche size," Nature, vol. 425, no. 6960, pp. 836-841, 2003.

[20] A. W. Duncan, F. M. Rattis, L. N. DiMascio et al., "Integration of Notch and Wnt signaling in hematopoietic stem cell maintenance," Nature Immunology, vol. 6, no. 3, pp. 314-322, 2005.

[21] S. J. C. Mancini, N. Mantei, A. Dumortier, U. Suter, H. R. MacDonald, and F. Radtke, "Jagged1-dependent Notch signaling is dispensable for hematopoietic stem cell selfrenewal and differentiation," Blood, vol. 105, no. 6, pp. 2340 2342, 2005.

[22] I. Maillard, U. Koch, A. Dumortier et al., "Canonical notch signaling is dispensable for the maintenance of adult hematopoietic stem cells," Cell Stem Cell, vol. 2, no. 4, pp. 356-366, 2008.

[23] A. T. Hooper, J. M. Butler, D. J. Nolan et al., "Engraftment and reconstitution of hematopoiesis is dependent on VEGFR2-mediated regeneration of sinusoidal endothelial cells," Cell Stem Cell, vol. 4, no. 3, pp. 263-274, 2009.

[24] J. M. Butler, D. J. Nolan, E. L. Vertes et al., "Endothelial cells are essential for the self-renewal and repopulation of Notchdependent hematopoietic stem cells," Cell Stem Cell, vol. 6, no. 3, pp. 251-264, 2010.

[25] J. M. Butler, H. Kobayashi, and S. Rafii, "Instructive role of the vascular niche in promoting tumour growth and tissue repair by angiocrine factors," Nature Reviews Cancer, vol. 10, no. 2, pp. 138-146, 2010.

[26] U. Blank, G. Karlsson, and S. Karlsson, "Signaling pathways governing stem-cell fate," Blood, vol. 111, no. 2, pp. 492-503, 2008.

[27] F. J. T. Staal and T. C. Luis, "Wnt signaling in hematopoiesis: crucial factors for self-renewal, proliferation, and cell fate decisions," Journal of Cellular Biochemistry, vol. 109, no. 5, pp. 844-849, 2010.

[28] J. J. Trowbridge, A. Xenocostas, R. T. Moon, and M. Bhatia, "Glycogen synthase kinase-3 is an in vivo regulator of hematopoietic stem cell repopulation," Nature Medicine, vol. 12, no. 1, pp. 89-98, 2006.

[29] T. Reya, A. W. Duncan, L. Ailles et al., "A role for Wnt signalling in self-renewal of haematopoietic stem cells," Nature, vol. 423, no. 6938, pp. 409-414, 2003.

[30] H. M. Lee, H. Zhang, V Schulz, D. P. Tuck, and B. G. Forget, "Downstream targets of HOXB4 in a cell line model of primitive hematopoietic progenitor cells," Blood, vol. 116, pp. 720-730, 2010.

[31] J. Jiang, H. Yu, Y. Shou et al., "Hemgn is a direct transcriptional target of HOXB4 and induces expansion of murine myeloid progenitor cells," Blood, vol. 116, pp. 711-719, 2010.

[32] T. Yamane, T. Kunisada, H. Tsukamoto et al., "Wnt signaling regulates hemopoiesis through stromal cells," Journal of Immunology, vol. 167, no. 2, pp. 765-772, 2001.

[33] C. Cerdan and M. Bhatia, "Novel roles for Notch, Wnt and Hedgehog in hematopoesis derived from human pluripotent stem cells," International Journal of Developmental Biology, vol. 54, no. 6-7, pp. 955-964, 2010.
[34] W. Goessling, T. E. North, S. Loewer et al., "Genetic interaction of PGE2 and Wnt signaling regulates developmental specification of stem cells and regeneration," Cell, vol. 136, no. 6, pp. 1136-1147, 2009.

[35] N. Wang, H.-G. Kim, C. V. Cotta et al., “TGF $\beta /$ BMP inhibits the bone marrow transformation capability of Hoxa9 by repressing its DNA-binding ability," EMBO Journal, vol. 25, no. 7, pp. 1469-1480, 2006.

[36] F. Arai, A. Hirao, M. Ohmura et al., “Tie2/angiopoietin-1 signaling regulates hematopoietic stem cell quiescence in the bone marrow niche," Cell, vol. 118, no. 2, pp. 149-161, 2004.

[37] A. Wilson, M. J. Murphy, T. Oskarsson et al., "c-Myc controls the balance between hematopoietic stem cell self-renewal and differentiation," Genes and Development, vol. 18, no. 22, pp. 2747-2763, 2004.

[38] J. Zhang, G. J. Woodhead, S. K. Swaminathan et al., "Cortical neural precursors inhibit their own differentiation via Ncadherin maintenance of beta-catenin signaling," Developmental cell, vol. 18, no. 3, pp. 472-479, 2010.

[39] J. M. Rowlinson and M. Gering, "Hey2 acts upstream of Notch in hematopoietic stem cell specification in zebrafish embryos," Blood, vol. 116, no. 12, pp. 2046-2056, 2010.

[40] P. Cheng, A. Zlobin, V. Volgina et al., "Notch-1 regulates NF- $\kappa \mathrm{B}$ activity in hemopoietic progenitor cells," Journal of Immunology, vol. 167, no. 8, pp. 4458-4467, 2001.

[41] O. Bruserud and A. O. Kittang, "The Chemokine System in Experimental and Clinical Hematology," Current Topics in Microbiology and Immunology, vol. 870, pp. 3-12, 2010.

[42] $\varnothing$. Bruserud, A. Ryningen, A. M. Olsnes et al., "Subclassification of patients with acute myelogenous leukemia based on chemokine responsiveness and constitutive chemokine release by their leukemic cells," Haematologica, vol. 92, no. 3, pp. 332-341, 2007.

[43] D. Lee, C. Park, H. Lee et al., "ER71 acts downstream of BMP, Notch, and Wnt signaling in blood and vessel progenitor specification," Cell Stem Cell, vol. 2, no. 5, pp. 497-507, 2008.

[44] A. Sengupta, D. Banerjee, S. Chandra et al., "Deregulation and cross talk among Sonic hedgehog, Wnt, Hox and Notch signaling in chronic myeloid leukemia progression," Leukemia, vol. 21, no. 5, pp. 949-955, 2007.

[45] C. Müller-Tidow, B. Steffen, T. Cauvet et al., "Translocation products in acute myeloid leukemia activate the Wnt signaling pathway in hematopoietic cells," Molecular and Cellular Biology, vol. 24, no. 7, pp. 2890-2904, 2004.

[46] H. Reikvam, K. J. Hatfield, P. Lassalle, A. Olsnes Kittang, E. Ersvær, and $\varnothing$. Bruserud, "Targeting the angiopoietin (Ang)/Tie-2 pathway in the crosstalk between acute myeloid leukaemia and endothelial cells: studies of Tie-2 blocking antibodies, exogenous Ang-2 and inhibition of constitutive agonistic Ang-1 release," Expert Opinion on Investigational Drugs, vol. 19, no. 2, pp. 169-183, 2010.

[47] M. S. Thakar, X.-B. Zhang, B. C. Beard et al., "Transmission and expansion of HOXB4-induced leukemia in two immunosuppressed dogs: implications for a new canine leukemia model," Experimental Hematology, vol. 37, no. 10, pp. 1157-1166, 2009.

[48] H. Reikvam, A. M. Olsnes, B. T. Gjertsen, E. Ersvar, and O. Bruserud, "Nuclear factor-B signaling: a contributor in leukemogenesis and a target for pharmacological intervention in human acute myelogenous leukemia," Critical Reviews in Oncogenesis, vol. 15, no. 1-2, pp. 1-36, 2009. 
[49] $\varnothing$. Bruserud, "Acute myelogenous leukemia blasts as accessory cells during $\mathrm{T}$ lymphocyte activation: possible implications for future therapeutic strategies," Leukemia, vol. 13, no. 8, pp. 1175-1187, 1999.

[50] U. Koch, E. Fiorini, R. Benedito et al., "Delta-like 4 is the essential, nonredundant ligand for Notchl during thymic $\mathrm{T}$ cell lineage commitment," Journal of Experimental Medicine, vol. 205, no. 11, pp. 2515-2523, 2008.

[51] M. L. Janas, G. Varano, K. Gudmundsson, M. Noda, T. Nagasawa, and M. Turner, "Thymic development beyond $\beta$ selection requires phosphatidylinositol 3-kinase activation by CXCR4," Journal of Experimental Medicine, vol. 207, no. 1, pp. 247-261, 2010.

[52] B. R. Chitteti, Y.-H. Cheng, B. Poteat et al., "Impact of interactions of cellular components of the bone marrow microenvironment on hematopoietic stem and progenitor cell function," Blood, vol. 115, no. 16, pp. 3239-3248, 2010.

[53] D. Amsen, J. M. Blander, G. R. Lee, K. Tanigaki, T. Honjo, and R. A. Flavell, "Instruction of distinct CD4 T helper cell fates by different notch ligands on antigen-presenting cells," Cell, vol. 117, no. 4, pp. 515-526, 2004.

[54] S. Mukherjee, M. A. Schaller, R. Neupane, S. L. Kunkel, and N. W. Lukacs, "Regulation of $\mathrm{T}$ cell activation by Notch ligand, DLL4, promotes IL-17 production and Rorc activation," Journal of Immunology, vol. 182, no. 12, pp. 73817388, 2009.

[55] N. Kassner, M. Krueger, H. Yagita et al., "Cutting edge: plasmacytoid dendritic cells induce IL-10 production in T cells via the Delta-like-4/Notch axis," Journal of Immunology, vol. 184, no. 2, pp. 550-554, 2010.

[56] O. H. Cho, H. M. Shin, L. Miele et al., "Notch regulates cytolytic effector function in CD8+ T cells," Journal of Immunology, vol. 182, no. 6, pp. 3380-3389, 2009.

[57] Y. Maekawa, Y. Minato, C. Ishifune et al., "Notch2 integrates signaling by the transcription factors RBP-J and CREB1 to promote T cell cytotoxicity," Nature Immunology, vol. 9, no. 10, pp. 1140-1147, 2008.

[58] M. Jurynczyk, A. Jurewicz, C. S. Raine, and K. Selmaj, "Notch3 inhibition in myelin-reactive T cells down-regulates protein kinase $\mathrm{C} \theta$ and attenuates experimental autoimmune encephalomyelitis," Journal of Immunology, vol. 180, no. 4, pp. 2634-2640, 2008.

[59] G. F. Hoyne, I. Le Roux, M. Corsin-Jimenez et al., "Serrate1induced Notch signalling regulates the decision between immunity and tolerance made by peripheral CD4+ T cells," International Immunology, vol. 12, no. 2, pp. 177-185, 2000.

[60] S. Vigouroux, E. Yvon, H.-J. Wagner et al., "Induction of antigen-specific regulatory $\mathrm{T}$ cells following overexpression of a Notch ligand by human B lymphocytes," Journal of Virology, vol. 77, no. 20, pp. 10872-10880, 2003.

[61] J. B. Samon, A. Champhekar, L. M. Minter et al., "Notchi and TGF21 cooperatively regulate Foxp 3 expression and the maintenance of peripheral regulatory T cells," Blood, vol. 112, no. 5, pp. 1813-1821, 2008.

[62] E. Anastasi, A. F. Campese, D. Bellavia et al., "Expression of activated Notch3 in transgenic mice enhances generation of $\mathrm{T}$ regulatory cells and protects against experimental autoimmune diabetes," Journal of Immunology, vol. 171, no. 9, pp. 4504-4511, 2003.

[63] H. Kared, H. Adle-Biassette, E. Foïs et al., "Jagged2expressing hematopoietic progenitors promote regulatory $\mathrm{T}$ cell expansion in the periphery through notch signaling," Immunity, vol. 25, no. 5, pp. 823-834, 2006.

[64] Z. Jiao, W. Wang, M. Guo et al., "Expression analysis of Notch-related molecules in peripheral blood $\mathrm{T}$ helper cells of patients with rheumatoid arthritis," Scandinavian Journal of Rheumatology, vol. 39, no. 1, pp. 26-32, 2010.

[65] D. Ma, J. Dai, X. Zhu et al., "Aberrant expression of Notch signaling molecules in patients with immune thrombocytopenic purpura," Annals of Hematology, vol. 89, no. 2, pp. $155-161,2010$.

[66] P. Sodsai, N. Hirankarn, Y. Avihingsanon, and T. Palaga, "Defects in Notch1 upregulation upon activation of T cells from patients with systemic lupus erythematosus are related to lupus disease activity," Lupus, vol. 17, no. 7, pp. 645-653, 2008.

[67] L. M. Minter, D. M. Turley, P. Das et al., "Inhibitors of $\gamma$-secretase block in vivo and in vitro $\mathrm{T}$ helper type 1 polarization by preventing Notch upregulation of Tbx21," Nature Immunology, vol. 6, no. 7, pp. 680-688, 2005.

[68] W. Elyaman, E. M. Bradshaw, Y. Wang et al., "Jagged1 and deltal differentially regulate the outcome of experimental autoimmune encephalomyelitis," Journal of Immunology, vol. 179, no. 9, pp. 5990-5998, 2007.

[69] M. A. McGill and C. J. McGlade, "Mammalian Numb proteins promote Notch1 receptor ubiquitination and degradation of the Notch1 intracellular domain," Journal of Biological Chemistry, vol. 278, no. 25, pp. 23196-23203, 2003.

[70] C. M. Hustad, W. L. Perry, L. D. Siracusa et al., "Molecular genetic characterization of six recessive viable alleles of the mouse agouti locus," Genetics, vol. 140, no. 1, pp. 255-265, 1995.

[71] L. E. Matesic, D. C. Haines, N. G. Copeland, and N. A. Jenkins, "Itch genetically interacts with Notch1 in a mouse autoimmune disease model," Human Molecular Genetics, vol. 15, no. 24, pp. 3485-3497, 2006.

[72] A. Tyndall and F. Dazzi, "Chronic GVHD as an autoimmune disease," Best Practice and Research: Clinical Haematology, vol. 21, no. 2, pp. 281-289, 2008.

[73] T. Daikeler and A. Tyndall, "Autoimmunity following haematopoietic stem-cell transplantation," Best Practice and Research: Clinical Haematology, vol. 20, no. 2, pp. 349-360, 2007.

[74] J. Storek, M. Geddes, F. Khan et al., "Reconstitution of the immune system after hematopoietic stem cell transplantation in humans," Seminars in Immunopathology, vol. 30, no. 4, pp. 425-437, 2008.

[75] J. Storek, "Immunological reconstitution after hematopoietic cell transplantation-its relation to the contents of the graft," Expert Opinion on Biological Therapy, vol. 8, no. 5, pp. 583$597,2008$.

[76] T. J. Fry and C. L. Mackall, "Immune reconstitution following hematopoietic progenitor cell transplantation: challenges for the future," Bone Marrow Transplantation, vol. 35, no. 1, pp. S53-S57, 2005.

[77] O. Bruserud and O. Wendelboe, "Biological treatment in acute myelogenous leukaemia: how should T-cell targeting immunotherapy be combined with intensive chemotherapy?" Expert Opinion on Biological Therapy, vol. 1, no. 6, pp. 1005-1016, 2001.

[78] M. Jiménez, G. Ercilla, and C. Martínez, "Immune reconstitution after allogeneic stem cell transplantation with reduced-intensity conditioning regimens," Leukemia, vol. 21, no. 8 , pp. 1628-1637, 2007. 
[79] L. F. Porrata, M. A. Gertz, D. J. Inwards et al., "Early lymphocyte recovery predicts superior survival after autologous hematopoietic stem cell transplantation in multiple myeloma or non-Hodgkin lymphoma," Blood, vol. 98, no. 3, pp. 579$585,2001$.

[80] L. F. Porrata and S. N. Markovic, "Timely reconstitution of immune competence affects clinical outcome following autologous stem cell transplantation," Clinical and Experimental Medicine, vol. 4, no. 2, pp. 78-85, 2004.

[81] R. Parkman, G. Cohen, S. L. Carter et al., "Successful immune reconstitution decreases leukemic relapse and improves survival in recipients of unrelated cord blood transplantation," Biology of Blood and Marrow Transplantation, vol. 12, no. 9, pp. 919-927, 2006.

[82] D. H. Kim, S. K. Sohn, D. I. Won, N. Y. Lee, J. S. Suh, and K. B. Lee, "Rapid helper T-cell recovery above $200 \times 10^{6} / 1$ at 3 months correlates to successful transplant outcomes after allogeneic stem cell transplantation," Bone Marrow Transplantation, vol. 37, no. 12, pp. 1119-1128, 2006.

[83] J. Vela-Ojeda, M. A. García-Ruiz Esparza, E. ReyesMaldonado et al., "Clinical relevance of NK, NKT, and dendritic cell dose in patients receiving G-CSF-mobilized peripheral blood allogeneic stem cell transplantation," Annals of Hematology, vol. 85, no. 2, pp. 113-120, 2006.

[84] M. D. Porta, G. M. Rigolin, E. P. Alessandrino et al., "Dendritic cell recovery after allogeneic stem-cell transplantation in acute leukemia: correlations with clinical and transplant characteristics," European Journal of Haematology, vol. 72, no. 1, pp. 18-25, 2004.

[85] C. Talarn, A. Urbano-Ispizua, R. Martino et al., "Kinetics of recovery of dendritic cell subsets after reduced-intensity conditioning allogeneic stem cell transplantation and clinical outcome," Haematologica, vol. 92, no. 12, pp. 1655-1663, 2007.

[86] J. E. Talmadge, E. Reed, K. Ino et al., "Rapid immunologic reconstitution following transplantation with mobilized peripheral blood stem cells as compared to bone marrow," Bone Marrow Transplantation, vol. 19, no. 2, pp. 161-172, 1997.

[87] P. Dreger, K. Viehmann, N. von Neuhoff et al., "Autografting of highly purified peripheral blood progenitor cells following myeloablative therapy in patients with lymphoma: a prospective study of the long-term effects on tumor eradication, reconstitution of hematopoiesis and immune recovery," Bone Marrow Transplantation, vol. 24, no. 2, pp. 153-161, 1999.

[88] A. Galy, S. Rudraraju, R. Baynes, and J. Klein, "Recovery of lymphocyte and dendritic cell subsets after autologous CD34+ cell transplantation," Bone Marrow Transplantation, vol. 25, no. 12, pp. 1249-1255, 2000.

[89] C.-H. Pui, L. L. Robison, and A. T. Look, "Acute lymphoblastic leukaemia," The Lancet, vol. 371, no. 9617, pp. 1030-1043, 2008.

[90] L. W. Ellisen, J. Bird, D. C. West et al., "TAN-1, the human homolog of the Drosophila Notch gene, is broken by chromosomal translocations in T lymphoblastic neoplasms," Cell, vol. 66, no. 4, pp. 649-661, 1991.

[91] A. P. Weng, A. A. Ferrando, W. Lee et al., "Activating mutations of NOTCH1 in human T cell acute lymphoblastic leukemia," Science, vol. 306, no. 5694, pp. 269-271, 2004.

[92] A. P. Weng, J. M. Millholland, Y. Yashiro-Ohtani et al., "c-Myc is an important direct target of Notch1 in Tcell acute lymphoblastic leukemia/lymphoma," Genes and Development, vol. 20, no. 15, pp. 2096-2109, 2006.
[93] B. J. Feldman, T. Hampton, and M. L. Cleary, "A carboxyterminal deletion mutant of Notch1 accelerates lymphoid oncogenesis in E2A-PBX1 transgenic mice," Blood, vol. 96, no. 5, pp. 1906-1913, 2000.

[94] L. J. Beverly and A. J. Capobianco, "Perturbation of Ikaros isoform selection by MLV integration is a cooperative event in NotchIC-induced T cell leukemogenesis," Cancer Cell, vol. 3, no. 6, pp. 551-564, 2003.

[95] D. Allman, F. G. Karnell, J. A. Punt et al., "Separation of Notch1 promoted lineage commitment and expansion/transformation in developing T cells," Journal of Experimental Medicine, vol. 194, no. 1, pp. 99-106, 2001.

[96] J. R. Göthert, R. L. Brake, M. Smeets, U. Dührsen, C. G. Begley, and D. J. Izon, "NOTCH1 pathway activation is an early hallmark of SCLT leukemogenesis," Blood, vol. 110, no. 10, pp. 3753-3762, 2007.

[97] S. Breit, M. Stanulla, T. Flohr et al., "Activating NOTCH1 mutations predict favorable early treatment response and long-term outcome in childhood precursor T-cell lymphoblastic leukemia," Blood, vol. 108, no. 4, pp. 1151-1157, 2006.

[98] V. Asnafi, A. Buzyn, S. Le Noir et al., "NOTCH1/FBXW7 mutation identifies a large subgroup with favorable outcome in adult T-cell acute lymphoblastic leukemia (T-ALL): a Group for Research on Adult Acute Lymphoblastic Leukemia (GRAALL) study," Blood, vol. 113, no. 17, pp. 3918-3924, 2009.

[99] T. Palomero, K. McKenna, J. O-Neil et al., "Activating mutations in NOTCH1 in acute myeloid leukemia and lineage switch leukemias," Leukemia, vol. 20, no. 11, pp. 1963-1966, 2006.

[100] L. Fu, H. Kogoshi, N. Nara, and S. Tohda, "NOTCH1 mutations are rare in acute myeloid leukemia," Leukemia and Lymphoma, vol. 47, no. 11, pp. 2400-2403, 2006.

[101] S. Tohda, H. Kogoshi, N. Murakami, S. Sakano, and N. Nara, "Diverse effects of the Notch ligands Jagged1 and Deltal on the growth and differentiation of primary acute myeloblastic leukemia cells," Experimental Hematology, vol. 33, no. 5, pp. 558-563, 2005.

[102] S. Tohda and N. Nara, "Expression of Notch1 and Jagged1 proteins in acute myeloid leukemia cells," Leukemia and Lymphoma, vol. 42, no. 3, pp. 467-472, 2001.

[103] G.-H. Li, Y.-Z. Fan, X.-W. Liu et al., "Notch signaling maintains proliferation and survival of the HL60 human promyelocytic leukemia cell line and promotes the phosphorylation of the Rb protein," Molecular and Cellular Biochemistry, vol. 340, no. 1-2, pp. 7-14, 2010.

[104] P.-M. Chen, C.-C. Yen, W.-S. Wang et al., "Down-regulation of Notch-1 expression decreases PU.1-mediated myeloid differentiation signaling in acute myeloid leukemia," International Journal of Oncology, vol. 32, no. 6, pp. 1335-1341, 2008.

[105] P. J. M. Valk, R. G. W. Verhaak, M. A. Beijen et al., "Prognostically useful gene-expression profiles in acute myeloid leukemia," New England Journal of Medicine, vol. 350, no. 16, pp. 1617-1628, 2004.

[106] B. J. Wouters, M. A. Jordà, K. Keeshan et al., "Distinct gene expression profiles of acute myeloid/T-lymphoid leukemia with silenced CEBPA and mutations in NOTCH1," Blood, vol. 110, no. 10, pp. 3706-3714, 2007.

[107] T. Pabst and B. U. Mueller, "Complexity of CEBPA dysregulation in human acute myeloid leukemia," Clinical Cancer Research, vol. 15, no. 17, pp. 5303-5307, 2009. 
[108] R. Hubmann, J. D. Schwarzmeier, M. Shehata et al., "Notch2 is involved in the overexpression of CD23 in B-cell chronic lymphocytic leukemia," Blood, vol. 99, no. 10, pp. 3742-3747, 2002.

[109] E. Rosati, R. Sabatini, G. Rampino et al., "Constitutively activated Notch signaling is involved in survival and apoptosis resistance of B-CLL cells," Blood, vol. 113, no. 4, pp. 856-865, 2009.

[110] P. Secchiero, E. Melloni, M. G. Di Iasio et al., "Nutlin3 up-regulates the expression of Notch1 in both myeloid and lymphoid leukemic cells, as part of a negative feedback antiapoptotic mechanism," Blood, vol. 113, no. 18, pp. 43004308, 2009.

[111] T. Palomero, K. C. Barnes, P. J. Real et al., "CUTLL1, a novel human T-cell lymphoma cell line with $\mathrm{t}(7 ; 9)$ rearrangement, aberrant NOTCH1 activation and high sensitivity to $\gamma$ secretase inhibitors," Leukemia, vol. 20, no. 7, pp. 1279-1287, 2006.

[112] C. Stapnes, B. T. Gjertsen, H. Reikvam, and $\varnothing$. Bruserud, "Targeted therapy in acute myeloid leukaemia: current status and future directions," Expert Opinion on Investigational Drugs, vol. 18, no. 4, pp. 433-455, 2009.

[113] J. J. Everly, R. C. Walsh, R. R. Alloway, and E. S. Woodle, "Proteasome inhibition for antibody-mediated rejection," Current Opinion in Organ Transplantation, vol. 14, no. 6, pp. 662-666, 2009.

[114] M. J. Everly, J. J. Everly, B. Susskind et al., "Proteasome inhibition reduces donor-specific antibody levels," Transplantation Proceedings, vol. 41, no. 1, pp. 105-107, 2009.

[115] L. H. Mattingly, R. A. Gault, and W. J. Murphy, "Use of systemic proteasome inhibition as an immune-modulating agent in disease," Endocrine, Metabolic and Immune Disorders: Drug Targets, vol. 7, no. 1, pp. 29-34, 2007.

[116] C. Delaney, S. Heimfeld, C. Brashem-Stein, H. Voorhies, R. L. Manger, and I. D. Bernstein, "Notch-mediated expansion of human cord blood progenitor cells capable of rapid myeloid reconstitution," Nature Medicine, vol. 16, no. 2, pp. 232-236, 2010.

[117] K. Li, Y. Li, W. Wu et al., "Modulation of notch signaling by antibodies specific for the extracellular negative regulatory region of NOTCH3," Journal of Biological Chemistry, vol. 283, no. 12, pp. 8046-8054, 2008.

[118] K. Sugimoto, Y. Maekawa, A. Kitamura et al., "Notch2 signaling is required for potent antitumor immunity in vivo," Journal of Immunology, vol. 184, no. 9, pp. 4673-4678, 2010.

[119] M. Aste-Amézaga, N. Zhang, J. E. Lineberger et al., "Characterization of notch 1 antibodies that inhibit signaling of both normal and mutated notch1 receptors," PLoS One, vol. 5, no. 2, article e9094, 2010.

[120] Y. Wu, C. Cain-Hom, L. Choy et al., "Therapeutic antibody targeting of individual Notch receptors," Nature, vol. 464, no. 7291, pp. 1052-1057, 2010.

[121] T. Hoey, W.-C. Yen, F. Axelrod et al., "DLL4 blockade inhibits tumor growth and reduces tumor-initiating cell frequency," Cell Stem Cell, vol. 5, no. 2, pp. 168-177, 2009.

[122] R. E. Moellering, M. Cornejo, T. N. Davis et al., "Direct inhibition of the NOTCH transcription factor complex," Nature, vol. 462, no. 7270, pp. 182-188, 2009.

[123] C. Stapnes, A. P. Døskeland, K. Hatfield et al., "The proteasome inhibitors bortezomib and PR-171 have antiproliferative and proapoptotic effects on primary human acute myeloid leukaemia cells," British Journal of Haematology, vol. 136, no. 6, pp. 814-828, 2007.
[124] A. G. Clementz and C. Osipo, "Notch versus the proteasome: what is the target of gamma-secretase inhibitor-I?" Breast Cancer Research, vol. 11, no. 5, p. 110, 2009.

[125] G. Calandra, G. Bridger, and S. Fricker, "CXCR4 in clinical hematology," Current Topics in Microbiology and Immunology, vol. 870, pp. 173-191, 2010.

[126] K. Liseth, M. Sjo, K. Paulsen, $\varnothing$. Bruserud, and E. Ersvaer, "Early pre-engraftment, functional, in vitro responsiveness of T lymphocytes in allotransplanted, acute leukemia patients: proliferation and release of a broad profile of cytokines, possibly predictive of graft-versus-host disease," European Cytokine Network, vol. 21, no. 1, pp. 40-49, 2010.

[127] D. Deangelo, R. Stone, and L. Silverman, "A phase I clinical trial of the notch inhibitor MK-0752 in patients with Tcell acute lymphoblastic leukemia/ lymphoma (T-ALL) and other leukemias," Journal of Clinical Oncology, vol. 24, article 6585, 2006.

[128] A. Pannuti, K. Foreman, P. Rizzo et al., "Targeting Notch to target cancer stem cells," Clinical Cancer Research, vol. 16, no. 12, pp. 3141-3152, 2010.

[129] E. Weisberg, R. Barrett, Q. Liu, R. Stone, N. Gray, and J. D. Griffin, "FLT3 inhibition and mechanisms of drug resistance in mutant FLT3-positive AML," Drug Resistance Updates, vol. 12, no. 3, pp. 81-89, 2009.

[130] J. Zaia, L. Baden, M. J. Boeckh et al., "Viral disease prevention after hematopoietic cell transplantation," Bone Marrow Transplantation, vol. 44, no. 8, pp. 471-482, 2009.

[131] K. A. Marr, E. Bow, T. Chiller et al., "Fungal infection prevention after hematopoietic cell transplantation," Bone Marrow Transplantation, vol. 44, no. 8, pp. 483-487, 2009.

[132] E. S. Yvon, S. Vigouroux, R. F. Rousseau et al., "Overexpression of the Notch ligand, Jagged-1, induces alloantigenspecific human regulatory T cells," Blood, vol. 102, no. 10, pp. 3815-3821, 2003.

[133] M. Dominici, K. Le Blanc, I. Mueller et al., "Minimal criteria for defining multipotent mesenchymal stromal cells. The International Society for Cellular Therapy position statement," Cytotherapy, vol. 8, no. 4, pp. 315-317, 2006.

[134] W. A. Noort, A. B. Kruisselbrink, P. S. In't Anker et al., "Mesenchymal stem cells promote engraftment of human umbilical cord blood-derived CD34+ cells in NOD/SCID mice," Experimental Hematology, vol. 30, no. 8, pp. 870-878, 2002.

[135] L. M. Ball, M. E. Bernardo, H. Roelofs et al., "Cotransplantation of ex vivo-expanded mesenchymal stem cells accelerates lymphocyte recovery and may reduce the risk of graft failure in haploidentical hematopoietic stem-cell transplantation," Blood, vol. 110, no. 7, pp. 2764-2767, 2007.

[136] J. M. Weber and L. M. Calvi, "Notch signaling and the bone marrow hematopoietic stem cell niche," Bone, vol. 46, no. 2, pp. 281-285, 2010.

[137] Y.-H. Hu, D.-Q. Wu, F. Gao, G.-D. Li, and X.-C. Zhang, "Notch signaling: a novel regulating differentiation mechanism of human umbilical cord blood-derived mesenchymal stem cells into insulin-producing cells in vitro," Chinese Medical Journal, vol. 123, no. 5, pp. 606-614, 2010.

[138] F. A. Saleh, M. Whyte, P. Ashton, and P. G. Genever, "Regulation of mesenchymal stem cell activity by endothelial cells," Stem Cells and Development. In press.

[139] K. Le Blanc and O. Ringdén, "Immunomodulation by mesenchymal stem cells and clinical experience," Journal of Internal Medicine, vol. 262, no. 5, pp. 509-525, 2007. 
[140] S. Paczesny, S. W. Choi, and J. L. M. Ferrara, "Acute graft-versus-host disease: new treatment strategies," Current Opinion in Hematology, vol. 16, no. 6, pp. 427-436, 2009.

[141] T. Toubai, S. Paczesny, Y. Shono et al., "Mesenchymal stem cells for treatment and prevention of graft-versus-host disease after allogeneic hematopoietic cell transplantation," Current Stem Cell Research and Therapy, vol. 4, no. 4, pp. 252259, 2009.

[142] F. Liotta, R. Angeli, L. Cosmi et al., "Toll-like receptors 3 and 4 are expressed by human bone marrow-derived mesenchymal stem cells and can inhibit their T-cell modulatory activity by impairing notch signaling," Stem Cells, vol. 26, no. 1, pp. 279-289, 2008. 


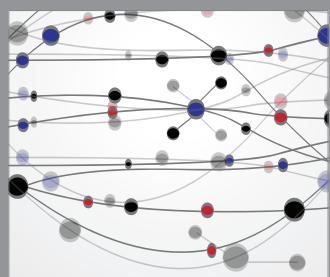

The Scientific World Journal
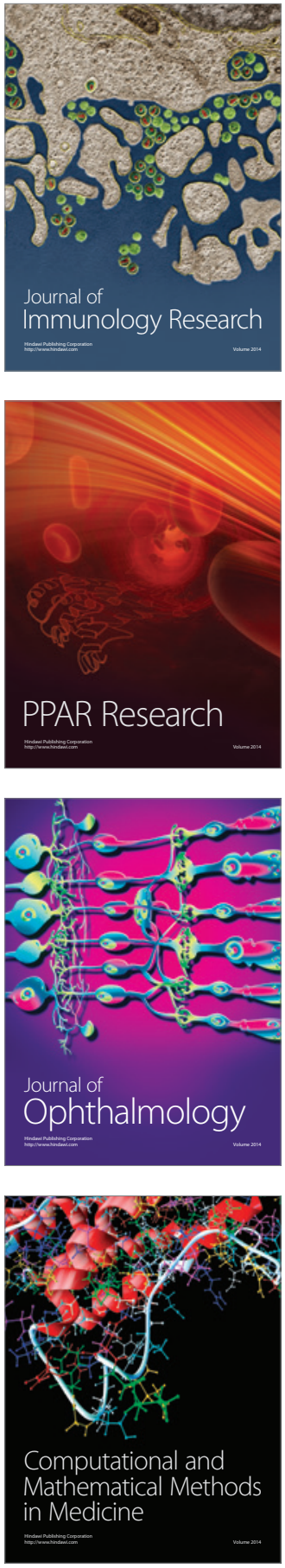

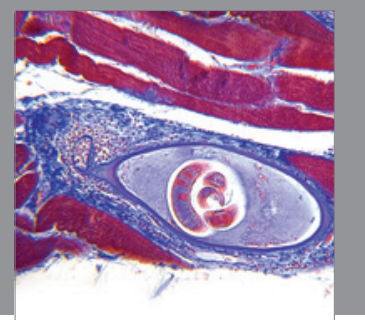

Gastroenterology

Research and Practice
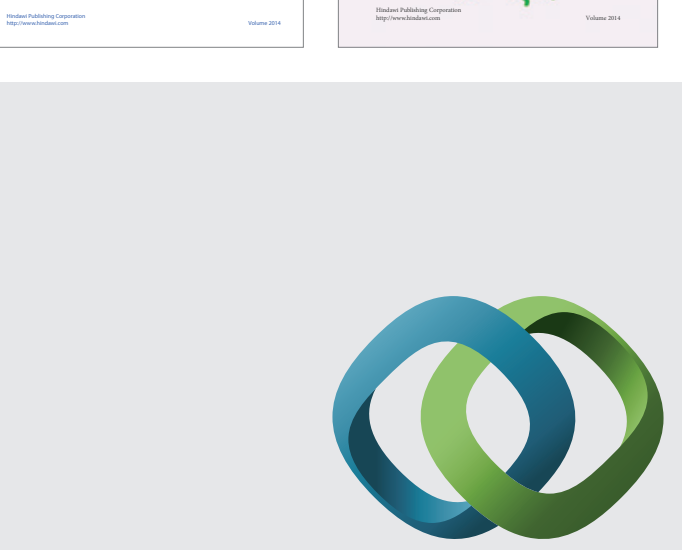

\section{Hindawi}

Submit your manuscripts at

http://www.hindawi.com
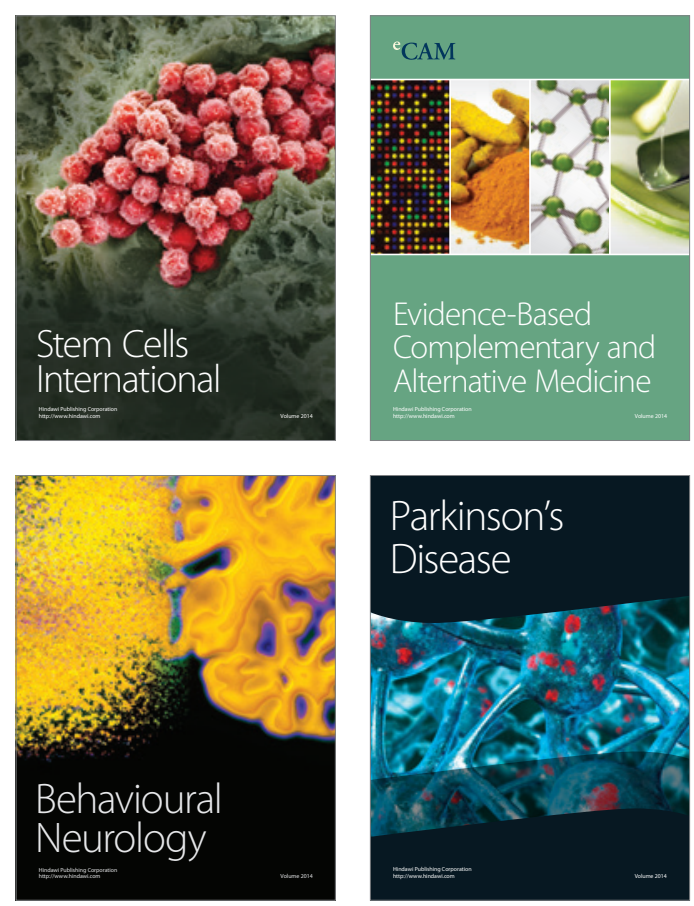

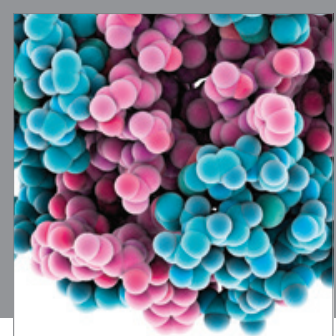

Journal of
Diabetes Research

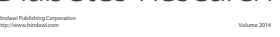

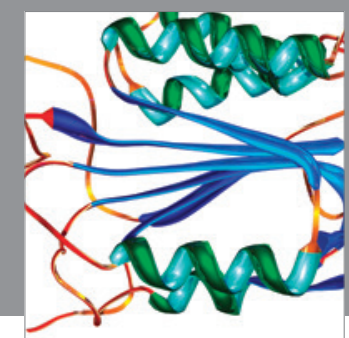

Disease Markers
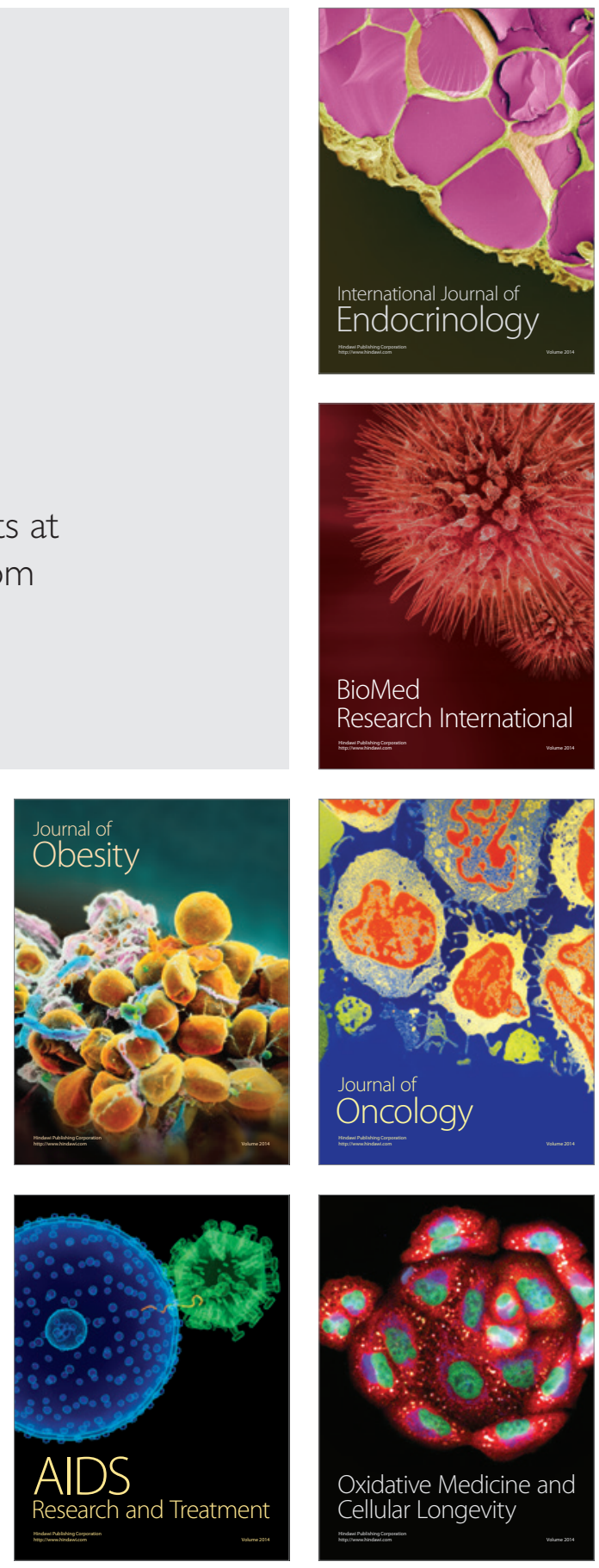